SOCRATES

\title{
SOCRATES 9 (Synopsis of Cochrane Reviews applicable to Emergency Services)
}

\author{
P Gilligan, D Hegarty, A Khan, M Shepherd, G Lumsden, G Kitching, A Taylor, H Law, J Brenchley, \\ J Jones
}

1 $\mathrm{n}$ this the ninth article of the SOCRATES series we present our synopses of reviews from the Cochrane Database of Systematic Reviews relating to obstetrics and gynaecology that the working party felt were of particular relevance to emergency medicine practitioners. The methods of our review and the rationale for the forming the SOCRATES working party are as have previously been published.

\section{NSAIDS FOR HEAVY MENSTRUAL BLEEDING Background}

Non-steroidal anti-inflammatory drugs (NSAIDs) reduce elevated prostaglandin levels in women with excessive menstrual bleeding and may also ease dysmenorrhoea.

\section{Results}

Nine trials with a total of 377 women were pooled for metaanalysis. A further seven trials with 99 participants in total were identified but could not be included in the metaanalysis as a result of their crossover design. The trials were not of consistently high quality. NSAIDs (naproxen or mefenamic acid) were equally more effective than placebo but inferior to danazol or tranexamic acid. Danazol had more significant side effects.

\section{SOCRATES says}

From the limited data available NSAIDs appear to be effective and well tolerated when used for the reduction of heavy menstrual bleeding.

A Lethaby A, Augood C, Duckitt K. NSAIDs for heavy menstrual bleeding (Cochrane Review). In: Cochrane Library, Issue 2. Oxford: Update Software, 2001.

\section{INTERVENTIONS FOR EMERGENCY CONTRACEPTION \\ Background}

About 50 million pregnancies are terminated worldwide each year. Emergency contraception is not widely used in many countries. This review aimed to examine the evidence for the success and complication rates of the various methods available.

\section{Results}

A total of 15 trials were included involving 12606 women. Mifepristone (RU 486) was more effective than the Yuzpe regimen (oestrogen and progestogen). The progestogen-only pill was more effective and better tolerated than the Yuzpe regimen, but not as effective as mifepristone.

\section{SOCRATES says}

\section{Berlipharm}

In the UK where the choice is between the Yuzpe regimen and the newer, progestogen-only pill (Levonelle, Berlipharm), the progestogen-only method is to be preferred on the grounds of greater efficacy and tolerability.

$\Delta$ Cheng L, Gulmezoglu AM, Ezcurra E, et al. Interventions for emergency contraception (Cochrane Review). In: Cochrane Library, Issue 2. Oxford: Update Software, 2001

\section{ANTIBIOTICS FOR INCOMPLETE ABORTION Background}

The World Health Organization estimates that as many as 20 million unsafe abortions are carried out each year and that $10-50 \%$ of women undergoing these abortions require medical care for complications (WHO, 1994). The use of antibiotics in individuals for septic abortion is well documented, and broad spectrum antibiotics with uterine evacuation reduce the morbidity and mortality in this condition. Routine prophylactic antibiotics for women coming in with presumed unsafe abortion is a question that remains to be answered. The aim of this review was to determine whether, from the best evidence currently available, routine use of prophylactic antibiotics should be recommended for women with incomplete abortion.

\section{Results}

One trial met the inclusion criteria of the review, and this included 140 women with evidence of incomplete abortion but who were apyrexial, had no abdominal tenderness, and did not have foul smelling vaginal discharge. Only $17.4 \%$ of the women took the tetracycline capsules. The study found no significant difference in the rates of post-abortal sepsis between the treatment and control groups.

\section{SOCRATES says}

Clinical judgement must be relied upon whether or not to prescribe prophylactic antibiotics in incomplete abortion as there is no robust evidence either to recommend or to abandon their use.

A May W, Gulmezoglu AM, Ba-Thike K. Antibiotics for incomplete abortion (Cochrane Review). In: Cochrane Library, Issue 4. Oxford: Update Software, 2000.

\section{INTERVENTIONS FOR NAUSEA AND VOMITING IN EARLY PREGNANCY \\ Background}

Nausea affects $70-85 \%$ of women in early pregnancy. Vomiting affects $50 \%$. The aetiology is unknown. Until fairly recently hyperemesis was a serious condition with a recorded mortality, and termination was practised when intravenous fluid replacement was less simple. The objective of this review was to assess the effectiveness of different methods of treating nausea and vomiting in early pregnancy.

\section{Results}

A total of 16 placebo controlled trials of varying quality comparing oral treatment for nausea were identified. A beneficial reduction in nausea was shown with all antiemetic drugs with no evidence of significant effects on fetal outcome. Side effects of sleepiness were noted. The four trials examining the use of acupressure did show an effect slightly less than that of antiemetic drugs. Pyridoxine did show some effect on nausea in higher doses. 


\section{SOCRATES says}

Antihistamine and phenothiazine antiemetic drugs are of value in treating nausea and vomiting in early pregnancy but there is some evidence of adverse effects. Also, there is very little information on effects on fetal outcomes.

A Jewell D, Young G. Interventions for nausea and vomiting in early pregnancy (Cochrane Review). In: Cochrane Library, Issue 4. Oxford: Update Software, 2000.

\section{TREATMENT FOR SYMPTOMATIC URINARY TRACT INFECTIONS DURING PREGNANCY Background}

Urinary tract infections (UTIs) occur in $17-20 \%$ of pregnancies and have been associated with prelabour rupture of membranes, preterm labour and delivery, clinical or subclinical chorioamnionitis, postpartum fever in the mother, and neonatal infection. They may also lead to serious maternal complications. This review sought to determine which treatment is most effective for symptomatic UTI during pregnancy in terms of cure rates, recurrent infections, preterm delivery, premature rupture of membranes, admission to neonatal intensive care unit, need for change of antibiotic, and incidence of prolonged pyrexia.

\section{Results}

Five randomised controlled trials were included which compared two different antibiotic regimens. The regimens included intramuscular (IM) cephalosporins compared with intravenous (IV) ampicillin and gentamicin, IM versus IV cephalosporins, once a day versus multiple dose cephalosporins and ampicillin versus nitrofurantoin. All trials were insufficiently powered to detect a significant difference between the regimens studied.

\section{SOCRATES says}

At this stage there is little high quality evidence to support one antibiotic regimen over another.

$\Delta$ Vazquez JC, Villar J. Treatments for symptomatic urinary tract infections during pregnancy (Cochrane Review). In: Cochrane Library, Issue 3. Oxford: Update Software, 2000

\section{CONCLUSION}

In this article the SOCRATES working party have summarised the reviews we felt were relevant to emergency practitioners in the Cochrane Database of Systematic Reviews relating to obstetrics and gynaecology. In the next issue we will present our synopses of reviews relating to gastroenterology and fluid management.

\section{ACKNOWLEDGEMENTS}

We would like to thank Dr Richard Hardern and the staff of the Postgraduate Medical Library at the General Infirmary at Leeds for their support and technical advice during the preparation of this paper.

\section{Authors' affiliations}

P Gilligan, A Khan, M Shepherd, G Lumsden, G Kitching, A Taylor, H Law, J Brenchley, J Jones, Specialist Registrars in Emergency

Medicine on the Yorkshire Rotation

D Hegarty, General Practitioner, Leeds, UK

Competing interests: none declared

Correspondence to: Dr P Gilligan, 1 Far Moss, Alwoodley, Leeds, Yorkshire LS17 7NU, UK; hegartydeirdre@ireland.com 